\title{
Uji Stabilitas Fisik Sediaan Sabun Padat Ekstrak Rimpang Temugiring (Curcuma heyneana Valeton \& Zijp)
}

\section{Physical Stability Test of Solid Soap of Temugiring (Curcuma heyneana Valeton \& Zijp) Rhizomes Extract}

\author{
lif Hanifa Nurrosyidah ${ }^{1 *}$, Milu Asri $^{1}$, Alfian Fachriddin Ma'ruf ${ }^{1}$ \\ ${ }^{1}$ Stikes Rumah Sakit Anwar Medika \\ Raya km 33 Jalan Bypass Krian, Jl. Parengan, Semawut, Balongbendo, \\ Kecamatan BalongBendo, Kabupaten Sidoarjo, Jawa Timur 61262, Indonesia \\ *Corresponding author email: iifnurrosyidah@yahoo.co.id
}

Received 28-5-2019 Accepted 11-12-2019 Available online 30-12-2019

\begin{abstract}
ABSTRAK
Kulit memiliki peranan yang sangat vital bagi manusia. Kulit berfungsi sebagai barier utama melawan infeksi, paparan zat kimia dan sinar matahari, dan kontaminan fisik lainnya sehingga kotoran akan mudah menempel pada kulit. Oleh karena itu, sangat penting menjaga dan memelihara kebersihan kulit untuk kesehatan. Sabun padat mampu membersihkan kotoran pada kulit. Kelemahan sabun padat yang selama ini beredar di pasaran adalah relatif menyebabkan kulit kering. Ekstrak temugiring (Curcuma heyneana Valeton \& Zijp) memiliki aktivitas sebagai antiradikal bebas dan mampu membantu menghaluskan kulit. Oleh karena itu dibutuhkan sebuah formulasi sabun padat yang mampu membersihkan, menghaluskan kulit, dan tidak menyebabkan kulit kering. Tujuan penelitian ini adalah melakukan studi formulasi sabun padat opaque dengan perbedaan konsentrasi ekstrak rimpang temugiring. Berdasarkan hasil penelitian diperoleh $\mathrm{pH}$ sabun padat ekstrak rimpang temu giring formula I,II, dan III sebesar 10. Nilai pH sediaan sabun memenuhi persyaratan sesuai literatur yaitu 9-11. Kadar air pada formula I, II, dan III sebesar berturut-turut 14; 14,55; dan 15\%. Kadar air sediaan memenuhi persyaratan SNI yaitu tidak lebih dari $15 \%$. Uji stabilitas busa sediaan sabun padat berkisar antara $73-95 \%$. Uji organoleptis sabun padat untuk aroma, warna, dan tekstur serta efek melembabkan untuk formula I, II, dan III memiliki nilai tingkat kesukaan yang sama.
\end{abstract}

Kata kunci: Curcuma heynaena Valeton \& Zijp, sabun padat. 


\begin{abstract}
The skin has a vital role as the main barrier against infection, exposure to chemicals, sunlight, and other physical contaminants for humans. Therefore, it is important to maintain skin hygiene for overall health. Solid soaps can clean dirt on the skin but it relatively also causes dry skin. A solid soap formulation capable of cleansing, softening the skin, and not causing dry skin is needed. The aim of this research is studying opaque solid soap formulations with temugiring (Curcuma heyneana Valeton \& Zijp) rhizomes extract as the active ingredient. The $\mathrm{pH}$ of temugiring extract solid soap in formula I, II, and III was 10, which met the requirement of standard soap (9-11). Their water content was 14, 14.55, and 15\%, respectively, which was also met SNI requirements (no more than 15\%). The foam stability of all solid soap formulas ranged from $73-95 \%$. All formulas of solid soap showed the same preference level in the organoleptic test, including aroma, color, and texture, as well as their moisturizing effect.
\end{abstract}

Key words: Curcuma heyneana Valeton \& Zijp, solid soap.

\section{Pendahuluan}

Kulit memiliki peranan yang sangat vital bagi manusia. Fungsi kulit antara lain meliputi proteksi, absorpsi, ekskresi, persepsi, pengaturan suhu tubuh (termoregulasi), dan pembentukan vitamin D. Kulit juga berperan sebagai barier infeksi. Fungsi kulit sedemikian rupa sehingga kotoran akan mudah menempel pada kulit. Oleh karena itu, sangat penting menjaga dan memelihara kebersihan kulit untuk kesehatan (Djuanda et al., 2007).

Bahan pembersihan kulit yang paling umum digunakan adalah air. Namun air saja tidak cukup mengangkat semua jenis kotoran. Pembersih dengan menambahkan surfaktan memiliki daya bersih kuat. Surfaktan adalah bahanbahan yang memperbaiki daya pembersih air karena memperbesar daya pembasah kulit serta mencegah partikelpartikel kotoran melekat pada kulit dengan jalan mengemulsinya, melarutkannya, dan mendispersikannya (Tranggono dan Latifah, 2007).

Sabun mandi merupakan senyawa natrium dengan asam lemak yang digunakan sebagai bahan pembersih tubuh, berbentuk padat, berbusa dengan atau tanpa penambahan zat lain, serta tidak menimbulkan iritasi pada kulit (SNI, 1994). Sabun padat dibedakan atas 3 jenis, yaitu sabun opaque, translucent, dan transparan. Sabun padat mampu membersihkan kotoran pada kulit. Salah satu parameter penting yang perlu diperhatikan dalam penentuan mutu sabun mandi adalah banyaknya busa yang dihasilkan. Busa mempunyai peranan penting dalam proses pembersihan kulit dan menghantarkan wangi dari sabun (Hernani et al., 2010). Surfaktan diperlukan untuk meningkatkan kualitas busa pada sabun (Wijana et al., 2005). Kelemahan sabun padat yang selama ini beredar di pasaran adalah relatif menyebabkan kulit kering akibat 
kandungan surfaktannya. Oleh karena itu dibutuhkan sebuah formulasi sabun padat yang mampu membersihkan, menghaluskan kulit, dan tidak menyebabkan kulit kering.

$$
\text { Rimpang temugiring }
$$

mengandung senyawa antara lain minyak atsiri, kurkumin, tanin, saponin, flavonoid, dan pati. Pada beberapa penelitian terbukti bahwa ekstrak temugiring memiliki efek perlindungan terhadap bahaya yang ditimbulkan oleh sinar UV. Berdasarkan penelitian yang telah dilakukan oleh Wijayakusuma (2002) dan Hernani et al. (2002) menyebutkan bahwa rimpang temugiring mempunyai aktivitas antioksidan yang cukup tinggi.

Secara tradisional rimpang temugiring mempunyai beberapa khasiat antara lain sebagai obat luka, obat cacing, obat sakit perut, obat pelangsing, memperbaiki warna kulit, obat untuk mengatasi perasaan tidak tenang atau cemas, jantung berdebar-debar, haid tidak teratur, obat rematik, menambah nafsu makan, meningkatkan stamina, menghaluskan kulit, obat jerawat, obat cacar air, dan obat batuk (Wijayakusuma, 2002). Berbagai merk kosmetik tradisional telah menggunakan ekstrak daun temugiring seperti lulur mandi, masker wajah, dan peeling.

Pada penelitian ini, dibuat tiga formula sabun padat yang mengandung ekstrak rimpang temugiring dalam konsentrasi yang berbeda dan kombinasi minyak zaitun dan minyak kelapa yang diharapkan mampu menghasilkan sabun padat yang efektif untuk membersihkan kulit dan memberikan efek lembab pada kulit. Ekstrak rimpang temugiring diharapkan mampu memberikan efek lembut pada kulit.

\section{Metode Penelitian}

Alat dan Bahan

Alat yang digunakan pada pembuatan produk sabun padat adalah beker gelas, gelas ukur, erlenmeyer, mantel Jacket (baskom berisi air dingin), mixer (hand blender), alat cetak sabun, $\mathrm{pH}$ meter, timbangan analitik (Ohaus ${ }^{\circledR}$ ), dan hot plate. Bahan yang digunakan pada pembuatan produk sabun padat adalah cocounut oil, olive oil, $\mathrm{NaOH}$, rimpang temugiring, akua demineralisata, dan cocoamid DEA. Formula produk sabun padat dapat dilihat pada Tabel 1.

Tabel 1. Formula sediaan sabun padat

\begin{tabular}{lccc}
\hline \multirow{2}{*}{ Bahan } & \multicolumn{3}{c}{ Jumlah bahan (\%) } \\
\cline { 2 - 4 } & F1 & F2 & F3 \\
\hline Ekstrak Rimpang Temugiring & 20 & 15 & 10 \\
Minyak Kelapa & 40 & 40 & 40 \\
Minyak Zaitun & 20 & 20 & 20 \\
NaOH & 9 & 9 & 9 \\
Cocoamid DEA & 10 & 10 & 10 \\
Aqua Demineralisata & Ad $100 \%$ & Ad $100 \%$ & $\mathrm{Ad} 100 \%$ \\
\hline
\end{tabular}


Jalannya Penelitian

Ekstrak rimpang temugiring
dibuat dengan metode maserasi. Sebanyak 500 gram simplisia temugiring dihaluskan kemudian dimaserasi dengan pelarut etanol $96 \%$ selama tiga hari sambil diaduk. Filtrat yang diperoleh diuapkan dengan rotary evaporator. $\mathrm{NaOH}$ dilarutkan ke dalam akuades dan diaduk hingga larut dan diletakkan pada mantel jacket. Minyak nabati dicampur dengan cocamid DEA dan diaduk hingga berbusa menggunakan hand blander, kemudian larutan $\mathrm{NaOH}$ dicampur dengan campuran minyak dan diaduk sampai merata. Campuran ini kemudian ditambah ekstrak kental temugiring yang sudah dilarutkan terlebih dahulu, sehingga terbentuk masa sabun yang selanjutnya dituang pada cetakan. Sabun padat yang sudah memadat kemudian dibiarkan selama satu minggu untuk kemudian dilakukan evaluasi sediaan sabun padat yang meliputi uji organoleptis (bau dan warna), $\mathrm{pH}$ sediaan, kadar air, dan uji stabilitas busa.

\section{Hasil dan Pembahasan}

Evaluasi sediaan sabun padat yang mengandung ekstrak rimpang temugiring pada penelitian ini dilakukan untuk mendapatkan sediaan sabun ekstrak temugiring dengan mutu yang baik. Uji yang dilakukan meliputi pemeriksaan mutu sabun mandi yaitu organoleptis, kadar air, stabilitas busa, dan $\mathrm{pH}$ yang ditunjukan pada Tabel 2 .

Tabel 2. Evaluasi sabun padat yang mengandung ekstrak rimpang temugiring

\begin{tabular}{lcc}
\hline Formula & Kadar Air \% & pH \\
\hline F1 & 14,00 & 10 \\
F2 & 14,55 & 10 \\
F3 & 15,00 & 10
\end{tabular}

Kadar air menunjukkan banyaknya kandungan air yang terdapat dalam suatu bahan (Suryani et al., 2002). Menurut SNI (1994), kadar air dalam sabun maksimum sebesar $15 \%$. Sabun yang sudah didiamkan selama satu minggu dievaluasi stabilitas busanya, hasil percobaan yang sudah dilakukan diperoleh kadar pada F1 $14,00 \%$, pada F2 14,55\%, dan pada F3 15,00\%. Kadar air pada sabun padat sesuai dengan persyaratan SNI karena tidak lebih dari
15\%. Terdapat perbedaan kadar setelah sabun baru selesai dibuat dengan sabun yang didiamkan selama satu minggu. Sabun yang baru selesai dibuat setelah memadat dan diuji kadar air menghasilkan lebih dari 50\%. Sehingga untuk memperoleh kadar air yang masuk rentang sediaan sabun hendaknya didiamkan minimal satu minggu untuk bisa digunakan.

Produk kosmetika terutama sabun memiliki karakteristik nilai $\mathrm{pH}$. 
Menurut Wasitaatmadja (2007), nilai pH yang sangat tinggi atau sangat rendah dapat menambah daya absorbsi kulit sehingga memungkinkan kulit teriritasi. Standar $\mathrm{pH}$ untuk sabun mandi berkisar antara 9-11 (Hernani et al., 2010). Nilai $\mathrm{pH}$ sabun setelah didiamkan selama satu minggu diperoleh $\mathrm{pH}$ pada F1, F2, dan F3 adalah 10. $\mathrm{pH}$ sediaan sabun masuk rentang yang dipersyaratkan yaitu antara 9-11. Sedangkan pH sediaan sabun yang baru setelah dibuat menunjukkan pH 5 (asam).

Uji stabilitas busa bertujuan untuk mengetahui kestabilan busa yang dihasilkan oleh sabun padat, dengan penambahan cocomid DEA 10\% sebagai surfaktan dan penstabil busa pada sabun. Menurut DeRagon et al. (1968) kriteria stabilitas busa yang baik yaitu, apabila dalam waktu 5 menit diperoleh kisaran stabilitas busa antara $60-70 \%$. Pada percobaan ini dalam waktu 5 menit didapatkan kadar busa antara 94-95\%, hal ini sudah memenuhi persyaratan. Parameter yang digunakan adalah dengan melihat tinggi busa sabun padat pada tabung reaksi dan diamati penurunan busa tiap 5, 10, 20, dan 30 menit. Hasil stabilitas busa tiap menit menunjukkan bahwa formula dengan penambahan cocomid DEA yang sama (10\%) pada setiap formulasi yang mengandung perbedaan konsentrasi ekstrak temugiring dengan konsentrasi yang berbeda menunjukan nilai ratarata tinggi busa yang tidak berbeda pada semua formula.

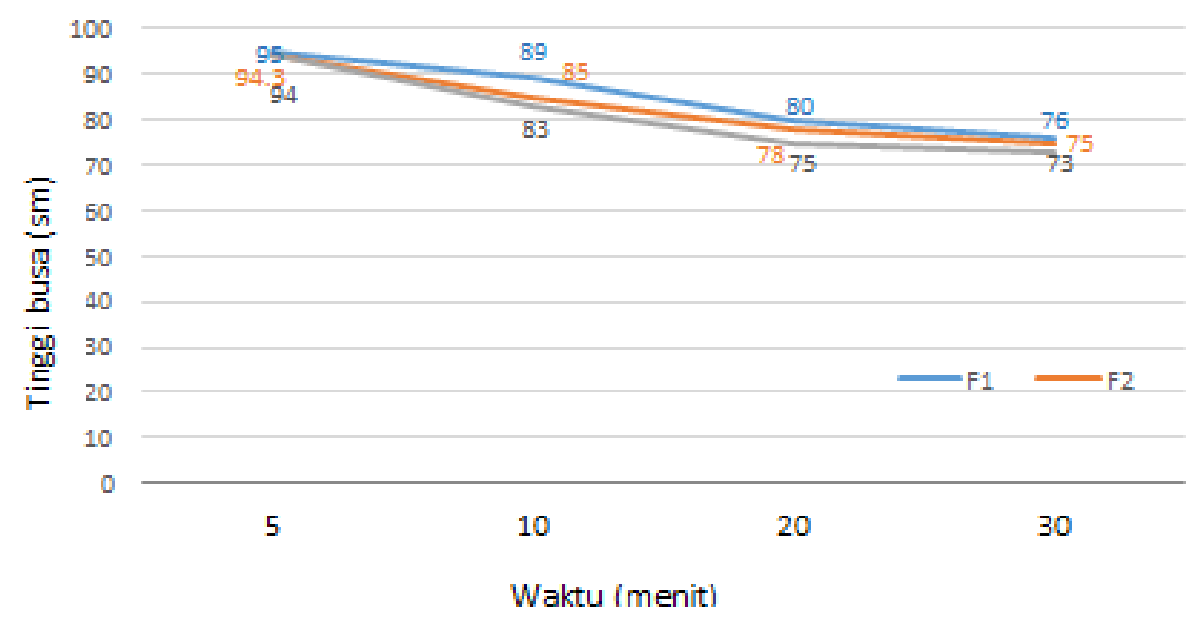

Gambar 1. Grafik uji stabilitas busa sabun padat ekstrak rimpang temugiring.

Uji organoleptis sediaan sabun padat dilakukan berdasarkan kuisoner terhadap dua puluh responden berdasarkan tingkat kesukaan terhadap parameter efek lembab di kulit, warna dan tekstur sabun, dan aroma sabun. Hasil uji dapat dilihat pada Gambar 2. 


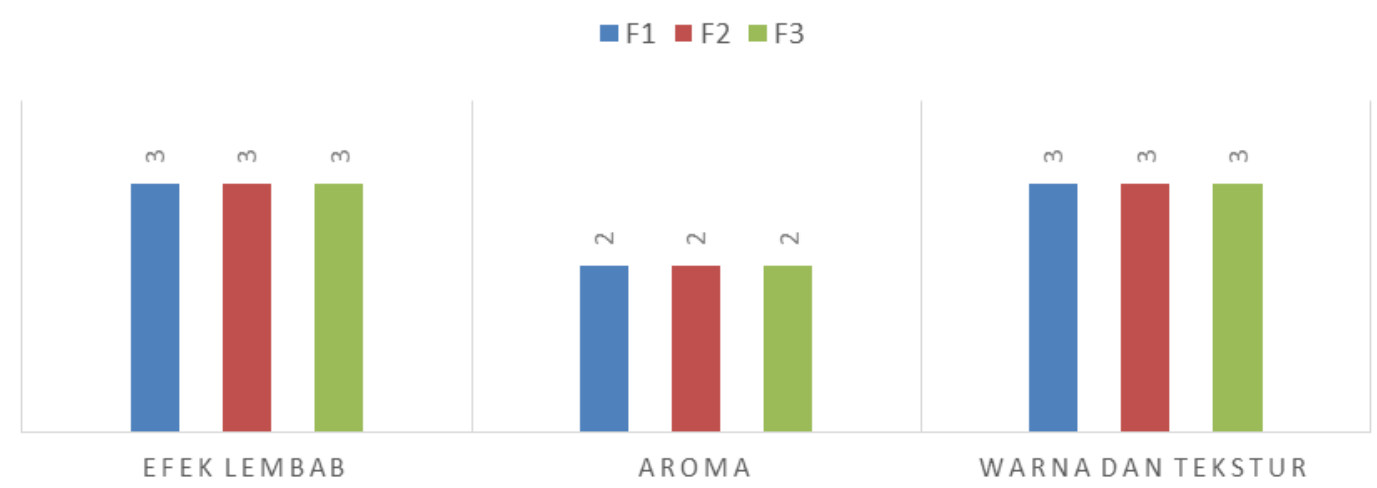

Gambar 2. Grafik uji organoleptis sabun padat ekstrak rimpang temugiring.

\section{Simpulan}

Berdasarkan hasil penelitian diperoleh kesimpulan bahwa $\mathrm{pH}$ sediaan sabun memenuhi persyaratan sesuai literatur yaitu 9-11. Kadar air sediaan memenuhi persyaratan SNI yaitu tidak lebih dari $15 \%$. Uji stabilitas busa sediaan sabun padat berkisar antara 73-95\% memenuhi persyaratan stabilitas busa pada sabun yaitu berkisar $60-70 \%$. Uji organoleptis sabun padat formula I memiliki nilai tertinggi dari segi aroma, sedangkan untuk warna dan tekstur serta efek melembabkan, formula I, II, dan III memiliki nilai tingkat kesukaan yang sama.

\section{Daftar Pustaka}

SNI 06-3532-1994. 1994. Sabun mandi. Badan Standardisasi Nasional.

DeRagon, S.A., Daley, P.M., Maso, H.F., and Conrad, L.I. 1968. Studies on lanolin derivatives in shampoo systems. Journal of the Society of Cosmetic Chemists, 20(13):777793.
Djuanda, A., Hamzah, M., Aisah, S. 2007. Ilmu Penyakit Kulit dan Kelamin. Jakarta: Fakultas Kedokteran Universitas Indonesia.

Hernani, Bunasor, T.K., Fitriati. 2010. Formula sabun transparan antijamur dengan bahan aktif ekstrak lengkuas (Alpinia galanga L. Swartz.). Buletin Penelitian Tanaman Rempah dan Obat, 21(2):192-205.

Suryani, A., Hambali, E., Kurniadewi, H. 2002. Kajian penggunaan lidah buaya (Aloe vera) dan bee pollen pada pembuatan sabun opaque, Journal of Agroindustrial Technology, 15(2):40-45.

Tranggono, R.I. dan Latifah, F. 2007. Buku Pegangan Ilmu Pengetahuan Kosmetik. Jakarta: PT. Gramedia Pustaka Utama.

Wasitaatmadja, S.M. 2007. Ilmu Penyakit Kulit dan Kelamin. Edisi kelima. Cetakan kedua. Jakarta: Fakultas Kedokteran Universitas Indonesia. 
Wijana, S., Mustaniroh, S.A., Wahyuningrum, I. 2005. Pemanfaatan minyak goreng bekas untuk pembuatan sabun: kajian lama penyabunan dan konsentrasi dekstrin. Jurnal
Teknologi Pertanian, 6(3):193202.

Wijayakusuma, H. 2002. Tumbuhan Berkhasiat Obat Indonesia: Rempah, Rimpang dan Umbi. Jakarta: Milenia Populer. 